\title{
Hitches in Antenatal Screening in Vaharai, Batticaloa, Sri Lanka
}

\author{
Markandu Thirukumar \\ Obstetrics and Gynaecology, Department of Clinical Science, Faculty of Health Care Science, Eastern University, \\ Vantharumoolai, Sri Lanka \\ Email: dr.thiru10@yahoo.com
}

How to cite this paper: Thirukumar, M. (2018) Hitches in Antenatal Screening in Vaharai, Batticaloa, Sri Lanka. Open Journal of Obstetrics and Gynecology, 8, 416-424. https://doi.org/10.4236/ojog.2018.84047

Received: March 20, 2018

Accepted: April 22, 2018

Published: April 25, 2018

Copyright (c) 2018 by author and Scientific Research Publishing Inc. This work is licensed under the Creative Commons Attribution International License (CC BY 4.0).

http://creativecommons.org/licenses/by/4.0/

\section{c) (i) Open Access}

\begin{abstract}
Women in developing countries are at more risk for pregnancy-related complications than their counterpart of developed countries. However, many of the complications are preventable with good quality antenatal care (ANC). This descriptive cross-sectional study was conducted among all the pregnant mothers who attend to routine antenatal clinic for booking visit at Vaharai, Batticaloa district of Sri Lanka during the time periods of 2015-2016. This study included 695 pregnant mothers. Among them majority were $(\mathrm{n}=661$; 95.1\%) Tamil and belong to $(\mathrm{n}=587 ; 84.5 \%)$ average age of 19 to 35 years. Majority of pregnant mothers studied up to grade eleven (GCE O/L) ( $\mathrm{n}=484$; 69.6\%). Among them $14.4 \%$ were identified as anaemic. Among anaemic mothers $8.4 \%$ were mild, $5.2 \%$ were moderate \& $0.8 \%$ severe anaemic. There was no statistically significant difference between ethnicity, parity of pregnant mothers, \& their respective haemoglobin levels. Most pregnant mothers belong to $(\mathrm{n}=338 ; 48.6 \%)$ blood group $\mathrm{O}$ and majority were $\mathrm{Rh}$ positive ( $\mathrm{n}=$ 603; 86.8\%). $90.6 \%$ of pregnant mothers underwent VDRL test and none was positive. This study shows that about $15 \%$ of first trimester pregnant mothers were anemic. Nutritional interventions for pre-pregnant women and educating pregnant women on prevention of anaemia, are recommended. Measures must also be taken to decrease teen age marriages.
\end{abstract}

\section{Keywords}

Anemia, Basic Investigations, Booking Visit, Batticaloa

\section{Introduction}

Pregnancy is an important life event for the women, her family and the whole society too. However, it can become critical for both mother and foetus when any complications arise. Early identification of those co-morbidities is helpful to 
minimize the complications related to pregnancy. Antenatal care (ANC), along with family planning, skilled delivery care and emergency obstetric care, are the four pillars aimed at improving maternal and new born health [1] [2].

Women in developing countries are at more risk for pregnancy-related complications than their counterpart of developed countries [3] [4]. However, many of the complications are preventable with good quality antenatal care (ANC) [5]. A trained health professional led antenatal care (ANC) is important for monitoring the pregnancy, to reduce potential risks for the mother and child during pregnancy and delivery. It will also help to achieve the Millennium Development Goals (MDGs) 4 of reducing child mortality by two-thirds and 5 of reducing the maternal mortality ratio by three-quarters by the year 2015 [6].

It is recommended that at least four ANC visits, spaced across regular intervals, and with a skilled attendant has been shown to improve health outcomes for both pregnant mothers and infants. The first antenatal care visit should occur with a skilled health attendant and as early as possible in the first trimester [7].

For optimal health outcomes, comprehensive ANC should contain each of the following four components, such identification of pre-existing conditions such as anaemia, HIV or hypertension, early detection of complications arising during pregnancy, such as gestational diabetes or preeclampsia, health promotion and disease prevention, including vaccines, nutrition counselling and micronutrient supplements and birth preparedness and complication planning, including breastfeeding counselling and antiretroviral therapy for HIV positive women [8].

In an antenatal clinic Haemoglobin level (Hb), Urine Full Report (UFR), Blood grouping and Rh, VDRL are routinely done in order to identify certain risk conditions. However, those tests are not freely available in field antenatal clinics in Sri Lanka. Anaemia in pregnancy, defined as haemoglobin concentration less than $11 \mathrm{~g} / \mathrm{dl}$, affects more than 56 million women globally, 2/3 of them being from Asia [9]. A study in the district of Anuradhapura in Sri Lanka revealed that prevalence of anaemia is less than $50 \%$ of the estimated prevalence for Sri Lanka [10].

Urinary tract infections (UTIs) during pregnancy are the commonest health problems worldwide, especially in developing countries. However, in Sri Lanka no studies have been done to identify prevalence of urinary tract infections during pregnancy [11].

Every pregnant mother is screened for Sexually Transmitted Infection (Syphilis antibodies-VDRL) and blood grouping and Rh. With regard to VDRL, 57.1\% were tested for VDRL at the clinic in 2014. There were 1464 field clinics with facilities to draw blood for VDRL testing during the year 2014. Out of the 350,941 mothers attending antenatal clinics, in $2014261(0.08 \%)$ were reported to be reactive for VDRL test [12].

Vaharai $\mathrm{MOH}$ division has a diverse population, which includes a population with different ethnicities and age groups. Still, there has been no study con- 
ducted to identify prevalence of anaemia in pregnant mothers in this area. Since haemoglobin levels are routinely measured at antenatal clinic, it was worthwhile to do a study based on these values.

In Sri Lanka, under the antenatal care, Hb level, UFR, Blood grouping \& Rh, VDRL and blood sugar level for screening for diabetic are routinely done as a basic investigation package at booking visit in order to identify certain risk factors early and to prevent late complications that related to those risk factors. Therefore, we analysed $\mathrm{Hb}$ level, Blood grouping \& $\mathrm{Rh}$ and VDRL test results together although there was no direct connection between those four investigations.

This study was conducted to analyse the patterns and to identify any co-relates of haemoglobin levels and other basic investigations; VDRL, Grouping \& $\mathrm{Rh}$ performed at booking and or subsequent visits to antenatal clinic in Vaharai $\mathrm{MOH}$, Batticaloa, Sri Lanka.

\section{Methods and Materials}

This descriptive cross-sectional study was conducted among all the pregnant mothers who attend to routine antenatal clinic for booking visit in $\mathrm{MOH}$ clinics at Vaharai MOH area between the time periods from 2015-2016.

When a woman embarks on pregnancy, she is registered for antenatal care and two sets of records are maintained; " $\mathrm{A}$ " card and " $\mathrm{B}$ " card. The " $\mathrm{A}$ " card is hand held by pregnant mothers and shown to health care workers. The " $\mathrm{B}$ " is maintained by midwives for record keeping. The entire $\mathrm{B}$ cards during the period of one year were collected for this study.

Data was extracted from the records available. Data extraction sheets were used to obtain data. All data were coded and entered in to SPSS 21 package and analysed.

\section{Results}

This study included 695 pregnant mothers. Among them majority were ( $\mathrm{n}=$ $661 ; 95.1 \%)$ Tamil and belong to average age of 19 to 35 years $(\mathrm{n}=587 ; 84.5 \%)$. Majority of pregnant mothers studied up to grade eleven (Table 1).

When haemoglobin level at booking visit is considered, 7\% pregnant mother's haemoglobin level measurement report is not recorded in the available B Card. Other mothers $\mathrm{Hb}$ reports shows that majority were not anaemic (85.6\%) and $14.4 \%(\mathrm{~N}=92)$ were identified as anaemic. Among anaemic mothers $8.4 \%$ were mild, $5.2 \%$ were moderate \& $0.8 \%$ severe anaemic. Among those 92 -anaemic mother's majority belongs to (91 out of 92) Tamil as well as (46 out of 92) primiparous mothers (Table 2). But there was no statistically significant difference between ethnicity of pregnant mothers \& their respective haemoglobin levels $(P>0.05)$ and no statistically significant difference between parity of pregnant mothers \& their respective haemoglobin levels $(P>0.05)$ (Table 3$)$.

The mean $\mathrm{Hb}$ levels with corresponding SD value are mentioned in Table 4. 
Table 1. Socio-demographic distribution of study sample.

\begin{tabular}{ccc}
\hline & Frequency & Percentage (\%) \\
Ethnicity & 661 & 95.1 \\
Tamil & 29 & 4.2 \\
Muslim & 05 & 0.7 \\
Sinhalese & & \\
Age category & 75 & 10.8 \\
Teenage (<19 years) & 587 & 84.5 \\
Average (19 - 35 years) & 33 & 4.7 \\
Elderly (>35 years) & & \\
Parity & 271 & 39.0 \\
P1 & 227 & 32.7 \\
P2 & 112 & 16.1 \\
P3 & 57 & 8.2 \\
P4 & 28 & 4.0 \\
P5 and above & 484 & 6.0 \\
Educational level & 154 & 22.2 \\
No schooling & 15 & 69.6 \\
Up to grade 5 & 484 \\
Up to GCE O/L & & 6.2 \\
Up to GCE A/L & &
\end{tabular}

Table 2. Prevalence of anaemia among ethnicities, age categories and parities.

\begin{tabular}{ccccc}
\hline & \multicolumn{2}{c}{ Anaemic mothers } & \multicolumn{2}{c}{ Non-Anaemic mothers } \\
\cline { 2 - 5 } & Frequency & Percentage (\%) & Frequency & Percentage (\%) \\
\hline Age category & & & & \\
Teenage (<19 years) & 10 & 13.7 & 63 & 86.3 \\
Average (19 - 35 years) & 80 & 14.9 & 458 & 85.1 \\
Elderly (>35 years) & 02 & 6.7 & 28 & 93.3 \\
Ethnicity & & & & \\
Tamil & 91 & 14.9 & 518 & 85.1 \\
Muslim & 01 & 3.6 & 27 & 96.4 \\
Sinhalese & 00 & 0.0 & 04 & 100.0 \\
Parity & & & & 82.0 \\
P1 & 46 & 18.0 & 210 & 86.8 \\
P2 & 27 & 13.2 & 178 & 91.3 \\
P3 & 09 & 8.7 & 95 & 86.5 \\
P4 & 07 & 13.5 & 45 & 87.5 \\
P5 and above & 03 & 12.5 & 21 & \\
\hline
\end{tabular}

$\mathrm{N}=54$ of pregnant mothers didn't undergone measurement of haemoglobin level at booking visit. 
Table 3. Association of anaemia vs ethnicity, age category and parity.

\begin{tabular}{cccc}
\hline Variable & Chi-square value/Likelihood Ratio Value & df & $P$ value \\
\hline Ethnicity & $5.11^{*}$ & 2 & 0.078 \\
Age category & 1.645 & 2 & 0.439 \\
Parity & 5.616 & 4 & 0.23 \\
\hline
\end{tabular}

${ }^{*}$ Likelihood Ratio value.

Table 4. Mean Hb level vs ethnicity, age category and parity.

\begin{tabular}{ccc}
\hline & Mean Hb level & SD \\
\hline Ethnicity & 10.67 & 3.03 \\
Tamil & 11.39 & 2.16 \\
Muslim & 9.7 & 4.88 \\
Sinhalese & & \\
Age category & 11.2 & 1.89 \\
Teenage (<19 years) & 10.62 & 3.11 \\
Average (19 - 35 years) & 10.87 & 3.41 \\
Elderly (>35 years) & & \\
Parity & 10.86 & 2.65 \\
P1 & 10.57 & 3.26 \\
P2 & 10.85 & 2.94 \\
P3 & 10.47 & 3.35 \\
P4 & 9.88 & 3.79 \\
P5 and above & &
\end{tabular}

According to their ethnicity, age group and parity. Distribution of Hb levels among study population is shown in Figure 1. Out of total pregnancies, majority belongs to ( $\mathrm{n}=338$; 48.6\%) blood group O (Figure 2) and majority were $86.8 \%$ $(\mathrm{n}=603)$ were $\mathrm{Rh}$ positive and $6.3 \%(\mathrm{n}=44)$ were $\mathrm{Rh}$ negative (Figure 3$)$. The results of VDRL test shows that $90.6 \%$ of pregnant mothers underwent the test and all results shows that none was positive.

\section{Discussion}

Poor antenatal care is an important risk factor for adverse outcomes among pregnant women. Vaharai $\mathrm{MOH}$ area has a population of 24,828 . It comprises of 10 PHM areas. The aim of this study was to analyze the patterns and identify the correlates of Hemoglobin levels and basic investigations (VDRL, Grouping \& $\mathrm{Rh}$ ) carried out at booking visit during pregnancy in Vaharai MOH area. No similar study was done in Vaharai $\mathrm{MOH}$ area and therefore it was worthwhile to do a study based on these investigations.

This study shows that $14.4 \%$ of first trimester pregnant mothers who presented at their booking visit to antenatal clinic were anaemic. In a study by Darshana I. L. A. N. et al. shows that nearly quarter of first trimester pregnant 


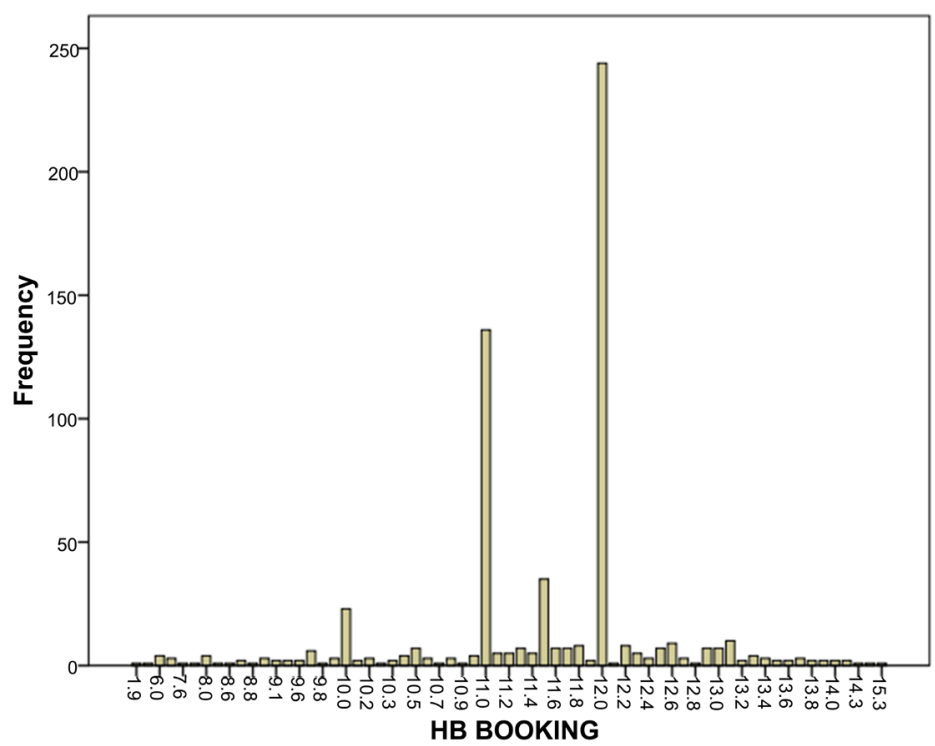

Figure 1. Distribution of haemoglobin level.

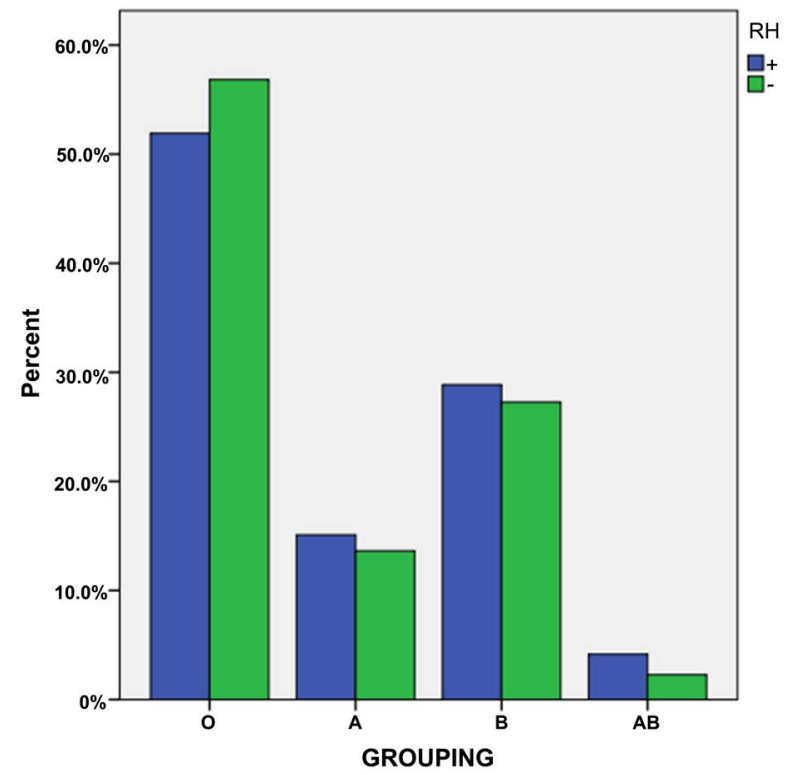

Figure 2. Blood group distribution among study sample.

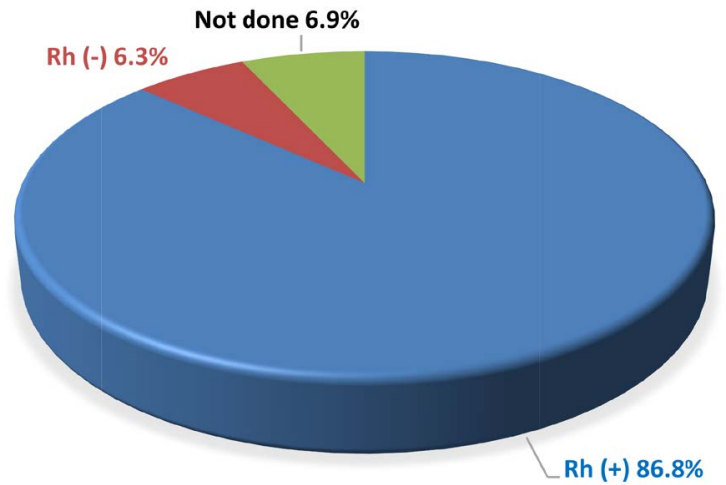

Figure 3. Prevalence of blood group category. 
mothers who presented at their booking visit to antenatal clinic were anemic [13].

In national figures only $57.1 \%$ pregnant mothers were screened for anaemia in 2014, but in this study 93\% pregnant mothers in Vaharai MOH area were screened. Therefore, the validity of the research is high due to high percentage of coverage.

This study further shows that among anaemic mothers $8.4 \%$ were mild, 5.2\% were moderate \& $0.8 \%$ severe anaemic. Among Sri Lankan pregnant mothers $57.1 \%$ are screened for anaemia at antenatal clinic visit in 2014. By them $9.4 \%$ anaemic mothers; $9.0 \%$ were mild or moderately anaemic $(\mathrm{Hb} 7-11 \mathrm{~g} / \mathrm{dl})$ while only $0.4 \%$ was severely anaemic $(\mathrm{Hb}<7 \mathrm{~g} / \mathrm{dl})$ [12]. Therefore, this study shows that the incidence of anaemia is more in Vaharai than the national figures. On the other hand, Darshana I. L. A. N. et al. in their study in Bope Poddala, Sri Lanka, has found that $8.3 \%$ had moderate anaemia and severe anaemia was not detected.

A prospective study was carried out at two Medical Officer of Health areas in Sri Lanka in 2010, to determine the effect of maternal $\mathrm{Hb}$ levels at booking visit on pregnancy outcome, including 817 pregnant mothers who were followed up until delivery. It showed that the prevalence of anemia $(\mathrm{Hb}<11 \mathrm{~g} / \mathrm{dl})$ was $7.1 \%$ (95\% CI 5.4\% - 8.9\%) [14].

Multiparity, teenage and elderly mothers are risk factors for anemia during the pregnancy. This study shows that incidence of anaemia more in multiparous than primiparous. However, the difference does not show statistically significance. The study in Bope Poddala, Sri Lanka shows that the prevalence of anemia during pregnancy was $19.6 \%$ among primiparous mothers and $33.3 \%$ among multiparous mothers which is very higher.

On the other hand, retrospective population-based cohort study in Finland revealed the prevalence of anemia during pregnancy was $2.5 \%$ among primiparous mothers and $2.3 \%$ among multiparous mothers [13].

Identification of blood group in pregnant mothers at booking visit will help with cross matching blood later if an emergency arises and identification the rhesus status will help to identify the possibility of rhesus isoimmunization. In Sri Lanka, $5 \%-7 \%$ of the population have the Rh-Negative Blood group. This study also shows that $6.3 \%$ had $\mathrm{Rh}$ Negative blood group which is similar national figures.

Syphilis among pregnant women causes up to 1.5 million perinatal deaths each year. All pregnant mothers in Sri Lanka are routinely screened for syphilis by performing VDRL test at booking visit and if VDRL positive, serological investigation is done to confirm the diagnosis of syphilis as well as for other sexually transmitted diseases.

In Sri Lanka Syphilis (all forms of syphilis) constituted 10\% of sexually transmitted infections in 2016 [15]. Overall $98.1 \%$ of pregnant mothers were tested for VDRL in Sri Lanka at the time of delivery. However, VDRL coverage at the time of delivery reported to be relatively low in RDHS areas of Colombo 
(83.1\%), Batticaloa (93.5\%) [12]. But in this studied $\mathrm{MOH}$ area of Vaharai only $90.6 \%$ of pregnant mothers underwent VDRL test and no positive cases was detected during the study period. Therefore, quality of antenatal care should be improved in Vaharai to increase the coverage of antenatal blood screening.

\section{Conclusion}

Quality of antenatal care should be improved to prevent anemia in pregnancy especially in remote places. Especially identification of anemia by low cost haemoglobin assessment should be improved. The health education should also be strengthened to prevent teen age marriage. As asymptomatic UTI causes complications in pregnancies study must be done in Sri Lanka to identify its true incidence.

\section{Acknowledgements}

I wish to express my sincere gratitude to Dr. Grace Regional Director Health Service, Batticaloa and Dr. Achchu than Medical Officer maternity and child health for providing me opportunity to do this research in Vaharai, Batticaloa. I thank to Mr. S. Santharuban, senior assistant librarian, Faculty of Health Care Science for his assistance in statistical analysis of the Data. I sincerely thank to my research assistant Dr. Hemika for tireless work. I also wish to express my gratitude to the officials especially public health midwives and other staff members of Vaharai Medical Officer Health who rendered their help during this research period.

\section{References}

[1] World Health Organization (2010) IMPAC Integrated Management of Pregnancy and Childbirth WHO Recommended Interventions for Improving Maternal and Newborn Health. World Health Organization, Geneva.

[2] Campbell, O.M.R. and Graham, W.J. (2006) Strategies for Reducing Maternal Mortality: Getting on with What Works. The Lancet, 368, 1284-1299.

https://doi.org/10.1016/S0140-6736(06)69381-1

[3] International Federation of Red Cross (2013) Maternal, New-Born and Child Health Framework. International Federation of Red Cross, Geneva.

[4] Tuncalp, O., Souza, J.P., Hindin, M.J., Santos, C.A., Oliveria, T.H., et al. (2014) Education and Severe Maternal Outcomes in Developing Countries: A Multi Country Cross Sectional Survey. BJOG: An International Journal of Obstetrics and $G y-$ naecology, 121, 57-65. https://doi.org/10.1111/1471-0528.12634

[5] WHO (2016) Neonatal Mortality. Global Health Observatory Data. World Health Organization, Geneva.

[6] Uganda Bureau of Statistics (UBOS) and Macro International Inc (2012) Uganda Demographic and Health Survey 2011. UBOS and Macro International Inc., Calverton, Maryland, USA.

[7] WHO (2007) Standards for Maternal and Neonatal Care. World Health Organization, Geneva.

[8] Minimum Package of Antenatal Care Services Defined. 
https://www.measureevaluation.org/prh/rh_indicators/womens-health/sm/minimu m-package-of-antenatal-care-services-defined

[9] Goonewardene, M., Shehata, M. and Hamad, A. (2012) Anaemia in Pregnancy. Best Practice \& Research Clinical Obstetrics \& Gynaecology, 26, 3-24.

https://doi.org/10.1016/j.bpobgyn.2011.10.010

[10] Chathurani, U., Dharshika, I., Galgamuwa, D., Wickramasinghe, N.D., Agampodi, T.C. and Agampodi, S.B. (2012) Anaemia in Pregnancy in the District of Anuradhapura, Sri Lanka-Need for Updating Prevalence Data\& Screening Strategies. Ceylon Medical Journal, 57, 101-106. https://doi.org/10.4038/cmj.v57i3.4148

[11] Dimetry, S.R., El-Tokhy, H.M., Abdo, N.M., Ebrahim, M.A. and Eissa, M. (2007) Urinary Tract Infection \& Adverse Outcome of Pregnancy Effect of Maternal Age on Pregnancy: A Retrospective Cohort Study. Journal of the Egyptian Public Health Association, 82, 203.

[12] Family Health Bureau (2014) Annual Report of Health 2014. Family Health Bureau, Sri Lanka.

[13] Räisänen, S., Kancherla, V., Gissler, M., Kramer, M.R. and Heinonen, S. (2014) Adverse Perinatal Outcomes Associated with Moderate or Severe Maternal Anaemia Based on Parity in Finland during 2006-10. Paediatric and Perinatal Epidemiology, 28, 372-380. https://doi.org/10.1111/ppe.12134

[14] http://siteresources.worldbank.org/INTPRH/Resources/STINoteFINAL26Feb08.pdf

[15] Abeysena, C., Jayawardana, P., de, A. and Seneviratne, R. (2010) Maternal Haemoglobin Level at Booking Visit and Its Effect on Adverse Pregnancy Outcome. Australian and New Zealand Journal of Obstetrics and Gynaecology, 50, 423-427. https://doi.org/10.1111/j.1479-828X.2010.01220.x 